\title{
ELECCIONES LEGISLATIVAS EN IRÁN
}

\author{
José Antonio Sainz de la Peña ${ }^{1}$ \\ UNISCI
}

\begin{abstract}
Resumen:
Las elecciones legislativas en Irán, una vez eliminados los reformistas se han celebrado en un clima de rivalidad. Las elecciones tenían que dejar claro quién mandaba en Irán, si los clérigos y el Guía el ayatolá Seyed Ali Jamenei o, el Presidente de la República, el laico Mahmud Ahmadineyad, apoyado en el Cuerpo de Guardias Revolucionarios. La realidad ha sido que las facciones conservadoras encabezadas por el Frente Unido Principalista, apoyados por el Guía Supremo, han obtenido el triunfo.
\end{abstract}

Palabras clave: Irán, Ali Khamenei, Mahmoud Ahmadinejad, Pasdaran, Principalistas, Elecciones 2012.

Title in English: "Legislative Elections in Iran".

Abstract:

The Legislative elections in Iran have been held in a climate of rivalry. The elections had to clarify who had the real political power in Iran, the clerics and the Supreme Leader, Ayatollah Seyed Ali Khamenei or the President of the Republic, the secular Mahmoud Ahmadinejad, supported by the Revolutionary Guard Corps. The reality was that the conservative faction led by the United Principalist Front, supported by the Supreme Leader, has obtained the victory.

Keywords: Iran, Ali Khamenei, Mahmoud Ahmadinejad, Pasdaran, United Principalist Front, Elections 2012.

Copyright (C) UNISCI, 2012.

Las opiniones expresadas en estos artículos son propias de sus autores, y no reflejan necesariamente la opinión de UNISCI. The views expressed in these articles are those of the authors, and do not necessarily reflect the views of UNISCI.

\footnotetext{
${ }^{1}$ José Antonio Sainz de la Peña es investigador senior de UNISCI.

E-mail: esedelape@hotmail.com.

http://dx.doi.org/10.5209/rev_UNIS.2012.n29.406"u
} 


\section{Introducción}

Durante los últimos meses la actividad política iraní ha estado centrada en las elecciones para el $9^{\circ}$ Maylis (Asamblea Consultiva Islámica o Parlamento) de la República Islámica.

Otro asunto importante, éste de política internacional, ha sido la evolución del problema del programa nuclear de Irán, con su secuencia de sanciones y amenazas, que sólo se cita aquí como recordatorio y por su utilización del nacionalismo para motivar a la población ante las elecciones.

\section{El periodo preelectoral}

Las elecciones para el $9^{\circ}$ Maylis han seguido las mismas pautas de los comicios anteriores, en especial las del 2008, - la población tiene el deber cívico y religioso de participar, la abstención es "haram" o sea algo prohibido por el Islam, la alta participación sirve para afianzar el régimen islámico y supone un duro golpe a los enemigos del mismo, en particular a las "potencias arrogantes", apelación al nacionalismo y sistema de filtrado de los candidatos por el Consejo de Guardianes para impedir la presencia de rivales-.

Sin embargo, estas elecciones han tenido dos particularidades que la han diferenciado de las precedentes: la ausencia, prácticamente total, de las facciones "reformistas" y "pragmáticas" del propio régimen y el enfrentamiento entre los dos sectores más duros del mismo.

En las elecciones anteriores la lucha electoral se realizaba entre facciones islámicas: por un lado los "reformistas", por otro los "pragmáticos" o "centristas" y por el tercero los "fundamentalistas" o "principalistas". Dentro de cada grupo se integraban en "Frentes" decenas de partidos u organizaciones que reflejaban intereses de grupúsculos e incluso de personas. Esta vez, reformistas y pragmáticos quedaron excluidos de la lucha electoral en la que, con escasas excepciones, sólo participaron los fundamentalistas.

\section{Los Reformistas}

Los principales jefes reformistas Musavi y Karrubi estaban en arresto domiciliario, otros políticos de segunda fila de la misma tendencia en la cárcel, sus medios de comunicación prohibidos y el conjunto calificado como "sedicioso" por las protestas habidas después de la elección presidencial de2008. No obstante, los diversos partidos reformistas, como el Frente de Participación, los Muyahidines de la Revolución Islámica, la Asociación de Clérigos Militantes, intentaron formar un "Frente" común para concurrir a la elección.

A pesar de que el Consejo de Coordinación del Frente Reformista se preparó para la elección y creó, en octubre, una página web con ese motivo, de que un Consejo de Coordinación de la Vía Verde hizo lo mismo, de que un diputado de la minoría reformista del Maylis asegurase que su grupo no boicotearía la elección, de que un dirigente de la Asociación de Clérigos Militantes dijese que no se consideraba la opción del boicot, de que se pidiese al Gobierno que se facilitase la participación de todos los grupos, en diciembre un dirigente reformista declaraba que, no obstante sus esfuerzos para que hubiese una elección 
correcta, los reformistas ni presentarían listas propias de candidatos ni apoyarían a nadie y el Secretario General de la Asociación de Clérigos, Musavi Joeiniha, aseguraba lo mismo; es decir, que los reformistas boicotearían las elecciones. Los grupos reformistas habían elegido como reclamo la frase "Elecciones Limpias" y habían puesto como condiciones para entrar en la carrera electoral la liberación de las presos y detenidos, la liberalización del régimen y el reconocimiento de los derechos del pueblo, cosas que el régimen no podía otorgar a los "sediciosos".

Karrubi, a través de su mujer, hacía llegar al público una declaración irónica en la que sugería que, en vista de las circunstancias, un pequeño grupo de señores, aceptable por el régimen, se responsabilizase de las elecciones y eligiese directamente a los diputados. Además, decía que las autoridades querían organizar un simulacro de elecciones según el modelo de las presidenciales de 2009, con descalificaciones, anulaciones y urnas rellenas de votos falsos.

El ex Presidente Jatamí se expresaba diciendo que todos los indicios marcaban que no se debía participar en la elección, que la participación no tenía sentido. Pero el 19 de diciembre declaraba que, aunque los reformistas no debían presentar listas propias de candidatos, eso no quería decir que boicotearían la elección.

A título personal, algunos políticos reformistas se inscribieron como candidatos, entre ellos varias mujeres, algunos como independientes, otros insistiendo en sus ideas reformistas. Curiosamente, dos de esos candidatos habían sido miembros del Maylis en la $6^{\mathrm{a}}$ legislatura, fueron vetados por el Consejo de Guardianes para la $7^{\mathrm{a}}$ y $8^{\mathrm{a}}$, según ellos por error, y tenían la certeza de ser admitidos para la $9^{a}$. Una de las mujeres afirmaba que los reformistas podían participar en las elecciones por propia responsabilidad y que el movimiento reformista nunca cesaría de existir.

Según sus adversarios, los reformistas habían anunciado el boicot pero, probablemente, acabarían presentándose. Su idea era que, si los fundamentalistas pensaban que no tendrían enfrente un rival serio, resurgirían sus disensiones, no lograrían formar un frente común y entonces los reformistas explotarían la situación en su favor.

Tres partidos minoritarios, considerados como reformistas moderados o centristas, el Democrático, el de la Solidaridad y el de la Confianza Nacional, mantuvieron conversaciones, en diciembre, para ir en coalición a las elecciones. Explicaron que, ante la situación del país, los partidos reformistas no podían permanecer pasivos y debían tratar de impedir la ascensión al poder de grupos sin raíces e impopulares. Para ellos la prioridad era convencer a los reformistas que podían pasar el filtro del Consejo de Guardianes para que se presentasen como candidatos. Esta declaración se hacía el 26 de diciembre y la fecha límite de inscripciones era el día 30.

Para los fundamentalistas, la actitud de los reformistas era "hipócrita", de acuerdo con un sermón del predicador del viernes de Teherán, ayatolá Ahmad Jatamí, y que hablar de boicot era un reclamo "vacío". Dos semanas antes de las elecciones, un dirigente del grupo minoritario fundamentalista "La Voz de la Nación" criticaba a los reformistas por no haber sido más activos en la precampaña electoral, a pesar de lo cual, algunos reformistas figuraban en la lista de aquel partido ya que "entre los reformistas moderados y los fundamentalistas moderados no hay fronteras". Pero el jefe de la milicia "basiyi" criticaba al ex presidente Jatamí mandándole al "basurero de la historia", un alto jefe del Ejército vaticinaba que si el resultado de las elecciones no estaba en línea con "nuestros valores", el año 2012 sería 
"peligroso" e incluso "sangriento" y para el Frente de Resistencia de la Revolución Islámica, uno de los mayores grupos fundamentalistas, "los reformistas quieren establecer un régimen secular".

\section{Los Fundamentalistas/Principalistas}

En la República Islámica de Irán, las luchas políticas se realizan entre las facciones del régimen. Descartados los reformistas de la lucha electoral por su boicot a la misma, la contienda se redujo al enfrentamiento entre dos grupos, pertenecientes ambos al núcleo duro del régimen: uno, el Frente Unido Principalista (FUP), encabezado por el Guía Supremo (Rahbar) de la Revolución, el ayatolá Seyed Ali Jamenei; otro, el Frente de Resistencia de la Revolución Islámica FRRI) apoyado por el Presidente de la República, el laico Mahmud Ahmadineyad.

El enfrentamiento fue una lucha por el poder: el Presidente para tener el control del Maylis y asegurarse así una buena posición de partida para colocar a un hombre suyo en la elección presidencial del año próximo; el Rahbar para conservar la plenitud de su poder.

Sin embargo, esa lucha se enmascaró con una discusión religiosa, reviviendo una disputa teológica del siglo XVIII. Entonces el enfrentamiento tuvo lugar entre dos escuelas de pensamiento chií: una de ellas, la "ajbarí" predicaba que el creyente puede interpretar, sin necesidad de intermediarios, las tradiciones "ajbar" del Profeta y de los Imames, con lo que el clero es prescindible; la otra, la "usulî" afirmaba que los clérigos - los ulama- son necesarios para interpretar los "usul" o fundamentos o principios de la Ley y que todo creyente tiene la obligación de escoger un clérigo como "fuente de imitación" (marya-e taqlid) y seguir sus enseñanzas. La segunda escuela ganó la partida y de ahí viene el origen del sistema jerarquizado del clero chií.

El FUB sería el heredero de los "usulíes", por ello su grupo de denomina "usulgayarán”, fundamentalista o principalista, defiende la teoría del gobierno de los clérigos, del gobierno del alfaquí, el velayat-e faqih, y un Islam de tipo clerical, académico. Por el contrario, el FRRI sería el continuador de los "ajbaríes", apoya un Islam popular de carácter mesiánico y, en ocasiones, ha defendido un Islam sin clero. Ahmadineyad cree que el duodécimo Imam,el Mahdi, Mohamed, el "Señor del Tiempo", oculto desde el siglo XII, pero vivo, está a punto de volver a la tierra para llenarla de justicia cuando ahora lo está de iniquidad. El Rahbar no comparte esa teoría.

Aunque las diferencias entre un Islam popular y otro clerical existen, la verdad es que el enfrentamiento entre ambas facciones es ${ }^{2}$ por el control del poder político y que, al seguir el partido de Ahmadineyad el pensamiento "ajbarí”, ataca el sistema del velayat que es el fundamento de la República Islámica.

El FUP ha calificado al FRRI como "desviacionista" y un dirigente del primero, en una entrevista concedida a la agencia de noticias semipública Mehr, citaba las seis "características negativas" que permitían calificarlo de esa manera:

1. El FRRI no considera el principio del velayat-e faqih como punto de referencia para su actividad política y social,

\footnotetext{
2 “Deviant” current aptly named: MP”, Mehrnews, 24 December 2011.
} 
2. Dice que está en contacto con el Mahdi, lo que le aparta de la fe chií,

3. Algunos de sus miembros se relacionan con mujeres que no llevan el velo islámico (hiyab) correctamente y que no creen en los valores islámicos,

4. $\mathrm{Su}$ actitud relativa a las relaciones con los EEUU van en contra de las directrices marcadas por el difunto Imam Jomeini,

5. Quieren normalizar las relaciones con los EEUU, lo que implicaría reconocer la hegemonía americana,

6. Creen que las actuales revueltas populares en la región han sido organizadas por los EEUU y en vez de usar el término "despertar islámico" dicen "despertar humano".

En resumen, tres características religiosas y tres políticas que hacen que el FRRI sea considerado como una "corriente desviacionista por todos los revolucionarios e intelectuales islámicos".

En octubre, los mayores grupos principalistas se reunieron para crear un Comité para reforzar su unidad ante la proximidad de las elecciones-

A finales de octubre, Al Akbar Velayati, consejero del Guía y designado portavoz de FUP, se mostraba preocupado porque los esfuerzos para lograr la unidad de todos los grupos principalistas chocaban con la actitud de ciertos grupos que no cooperaban con el Comité. El FRRI, el más importante de los grupos, se negaba a aceptar las invitaciones del Comité como protesta por la forma en que se había creado.

A principio de noviembre, el Presidente de la Asamblea de Expertos, el ayatolá Kani, quién se había hecho cargo de la dirección de la corriente fundamentalista más importante, anunciaba que había mantenido contactos con el FRRI y, aunque era optimista sobre el resultado final, ese grupo insistía en no participar en el Comité. Un diputado del Maylis, de la mayoría fundamentalista, criticaba duramente al FRRI diciendo que estaba intentando desplazar a los verdaderos revolucionarios, que sus miembros eran unos oportunistas y ese Frente un instrumento en las manos de Ahmadineyad y de su Jefe de Gabinete Mashaii y por entonces, aunque se seguía diciendo que el FRRI todavía podía unirse al FUP, el Comité rechazó las condiciones de aquel para su participación y pronosticaba que presentaría listas propias para las elecciones.

A finales de noviembre, el FUP tuvo su primera reunión general de coordinación bajo el lema "Prudencia y Unidad bajo el paraguas del Vilayat". En ella se definió al Frente como la unión de las personas y facciones más importantes de los principalistas que apostaba por la unión de todas ellas.

El Presidente de la oficina electoral del FUP, Ali Reza Zakani, declaró que el Frente se había organizado gracias a los esfuerzos del Presidente de la Asamblea de Expertos y de la Sociedad del Clero Combatiente, ayatolá Kani, y el apoyo de la Asociación de Profesores del Seminario de Qom.

En la reunión se dijo que en el Frente no se admitirían diferencias de opinión que ocasionaran discordia o división del voto, que los candidatos de la lista apoyarían el sistema 
islámico y pidieron reforzar la unidad entre todos los grupos principalistas. Por otra parte, se afirmó que la estrategia del enemigo ante la elección sería provocar la división entre los poderes ejecutivo, legislativo y judicial y entre el pueblo y los políticos

Velayati declaró que todos los comprometidos con el sistema principalista tenían cabida en las listas del FUP así como que para proteger el sistema islámico y los intereses de la su revolución y del país no hay más alternativa que la principalistas. Por ello, todos los miembros del nuevo Maylis tienen que ser leales a los principios del velayat.

Por parte del FRRI, su Consejo Central declaraba que este Frente de oponía a la organización del FUP así como al mecanismo establecido para reforzar la unidad entre los grupos fundamentalistas. La hermana del Presidente, Parviz Ahmadineyad, se inscribía como candidata del FRRI diciendo que este Frente es sinónimo de Frente de la Revolución islámica y calificando a su hermano como "justiciero".

El Partido de la Coalición Islámica (Motelafeh), fundado por sugerencia del Imam Jomeini, considerado como conservador de derecha, con 120 parlamentarios en el $8^{\circ}$ Maylis, dudaba si presentar una lista propia dos días antes de cerrarse el plazo para la inscripción de candidatos.

\section{Declaraciones}

Durante el proceso electoral, todos los dirigentes del régimen hicieron multitud de declaraciones sobre las elecciones legislativas que fueron amplificadas por los medios de comunicación, en particular por la IRTB (radio y TV públicas). Las declaraciones pueden agruparse en cinco temas:

1. Importancia de las elecciones por ser éstas más sensibles para la estabilidad del régimen que otras anteriores por la situación política, por la importancia de Irán en el mundo y porque influirán en las elecciones presidenciales de 2013.

2. Necesidad de una participación masiva de la población para demostrar el enraizamiento del régimen islámico, renovar la alianza entre la nación y su dirección política, dar respuesta a los enemigos del extranjero y a los sediciosos del interior dando una "bofetada" a EEUU.

3. Descalificación de los rivales políticos tachándolos de sediciosos y de sirvientes de los intereses de los EEUU.

4. Ataques a los países occidentales asegurando tener pruebas de que los EEUU y las embajadas de la Unión Europea en Teherán intentaban utilizar las elecciones para provocar disturbios, socavar el régimen y amenazar su seguridad. También las sanciones económicas de la UE habrían sido programadas para influir en las elecciones. En especial fueron muy duras la respuesta a la creación de una "embajada virtual" norteamericana, que fue inmediatamente bloqueada por las autoridades iraníes y las acusaciones contra el Reino Unido.

5. Mensajes políticos a la población. Además de las insistentes llamadas para una participación masiva, críticas a "cierta gente" que quiere el boicot electoral, que la abstención es "haram", peticiones para que el Maylis quede en manos de religiosos y 
fundamentalistas, recordar que el pueblo puede en Irán elegir a sus dirigentes y solicitar vigilancia popular para hacer fracasar los complots contra el régimen.

En forma general y en todas las declaraciones, exaltación del nacionalismo iraní. De economía, cuya situación es desastrosa, con una inflación del 21\%, ni palabra (La cifra de inflación se ha duplicado durante los 7 años de presidencia de Ahmadineyad).

\section{Las elecciones}

El proceso electoral empezó legalmente con la inscripción de los candidatos entre el 24 y el 30 de diciembre. Los candidatos tenían que expresar, por escrito, su compromiso teórico y práctico con la Constitución y el Islam, ser mayores de edad y tener un grado universitario equivalente a un máster".

El día 31, el Ministro del Interior, Mohamed Najjar, informaba que 5.395 candidatos se habían inscrito, de ellos 428 mujeres, para optar a uno de los 290 escaños del Maylis. Entre los candidatos 260 eran ya diputados y 197 lo habían sido en legislaturas anteriores. En la circunscripción de Teherán, que es la mayor del país y elige 30 diputados, se presentaban 1066 candidatos, 157 eran mujeres.

Las minorías religiosas - judíos, zoroástricos, armenios del Norte, armenios del Sur y caldeos- que tienen asignados 14 puestos en el Maylis presentaron 42 candidatos.

El mismo día de la elección legislativa se celebraría otra elección para cubrir dos vacantes en la Asamblea de Expertos; para ellas se presentaron 18 clérigos.

A partir del 1 de enero empezó el examen de las calificaciones de los candidatos. Según el portavoz del Consejo de Guardianes, el día 28 habían sido autorizados a concurrir el 55\%, más de 2700; 1200 fueron rechazados y 333 se retiraron voluntariamente; el día 21 de febrero, después de un proceso de tres fases, el mismo portavoz comunicaba que 3444 candidaturas habían sido definitivamente aceptadas. Una treintena de miembros del $8^{\circ}$ Maylis que habían sido rechazados se unieron a la petición de boicot.

Basándose en encuestas oficiales y en sondeos privados, el Ministro de Interior pronosticaba una gran afluencia de votantes a las urnas.

La elección tuvo lugar el 2 de marzo y, antes de cerrar los colegios, en su sermón del viernes, el ayatolá Jamenei elogiaba la gran participación popular, que debilitaba a los enemigos del Islam, y a la que calificaba como "otro episodio épico de la historia de la República islámica”.

El Guía Supremo, en el momento de depositar su voto a primeras horas, reclamaba una participación "entusiasta y masiva", decía que el voto equivale a una plegaria que acerca al votante al Altísimo y la proporciona sus bendiciones.

El Ministro del Interior anunció, el día 4, los resultados finales: 225 candidatos habían sido elegidos miembros del $9^{\circ}$ Maylis, quedando para una segunda vuelta 65 escaños. Para obtener un escaño en la primera vuelta es preciso lograr más de $25 \%$ de los votos expresados; 
la segunda vuelta tendría lugar el 4 de mayo. La participación, de acuerdo con lo manifestado por el Ministro, había sido del $64 \%$, un $13 \%$ mayor que la de las elecciones para el $7^{\circ}$ y $8^{\circ}$, que sólo fue de $51 \%$.

En Teherán, únicamente se habían cubierto 5 de las 30 puestos disponibles, con una participación del 48\%, 17 puntos más que en 2008. En la capital, el candidato más votado fue Gholam Ali Haddad-Adel, consuegro del Guía Supremo. Quedaban 50 candidatos para ocupar 25 escaños.

Sobre la elección para la Asamblea de Expertos ni una palabra; es verdad que las elecciones para esa Asamblea no levantan ningún entusiasmo y que suelen tener una participación del orden del 30\%

Para el Ministro, la participación demostraba el fuerte apoyo popular al sistema islámico y al Guía, así como el rechazo a los "sediciosos" y un mensaje muy claro a Occidente. La nota ministerial añadía que los periodistas extranjeros que cubrían la elección habían quedado "asombrados" por el entusiasmo y la participación del pueblo iraní. Como curiosidad vale señalar que la nota decía que el número total de candidatos era de 3269, que no coincide con lo dicho anteriormente por el mismo Ministerio, algo normal en las elecciones iraníes.

En la elección las autoridades marcaron con tinta indeleble no sólo el documento de identificación de los votantes, sino también un dedo. Esta práctica pudiera explicar, en parte, el aumento de la participación popular ya que permite fácilmente saber si un ciudadano ha cumplido con su deber cívico y religioso. Es difícil saber si la tasa de participación popular anunciada por las autoridades es correcta, pues no hay medios para comprobarla, pero lo más probable es que esté falseada y que las elecciones hayan sido fraudulentas. En apoyo de esta opinión está el testimonio de los escasos periodistas occidentales que fueron autorizados a cubrir la jornada electoral. Estos periodistas no vieron ni entusiasmo ni multitudes votando. ${ }^{3}$

Igualmente es difícil conocer a qué grupo o facción pertenecen los nuevos diputados, exceptuados los principales políticos. Una estimación de un medio extranjero, generalmente fiable, adjudica los $3 / 4$ de los escaños a miembros del FUP y a otros grupos menores partidarios del Guía, es decir, unos 170 diputados; el resto, unos 55, se repartirían entre seguidores de Ahmadineyad y algunos independientes/reformistas testimoniales. En la segunda vuelta la proporción de fundamentalistas sería todavía mayor y con unos 215/220 diputados los seguidores del velayat-e faqih más estricto controlarían por completo el Maylis, lo que haría muy dura la vida del Presidente los meses que le quedan de mandato.

Como dato complementario, hacer notar que todos los candidatos para los puestos por Teherán partidarios de Ahmadineyad fueron eliminados por el Consejo de Guardianes y que su hermana fue derrotada por un candidato conservador. El ex Presidente, Jatamí, a pesar de sus declaraciones al inicio de la precampaña, fue a votar, lo que le valió ser acusado de traidor por los reformistas.

Después del día de las elecciones, el Guía, en diversas ocasiones, felicitó al pueblo de Irán por su participación, subrayó la importancia de la misma para la seguridad del país y que el pueblo había votado por el sistema político islámico, lo que representaba una "bofetada" a los "poderes arrogantes".

\footnotetext{
${ }^{3}$ New York Times, 2 March, 2012.
} 
Para el Presidente del Maylis, Lariyani, el resultado electoral era la prueba de la vaciedad de ciertos análisis políticos contra el sistema, del fracaso de Occidente y de la salvaguardia de los intereses nacionales y de los valores islámicos.

El ayatolá Yannati repetía las frases de la "bofetada" en la cara del enemigo y de la "épica" de la participación y en su sermón del día 23 explicaba que el retraso de la UE en aplicar sanciones había sido forzado por la gran participación en las elecciones.

Los medios de comunicación insistían en el "hecho inmenso, épico" de tal manera que la agencia oficial de noticias IRNA repetía exactamente las palabras del ayatola Jamenei y del Ministro del Interior sobre el "asombro" de los periodistas y la semioficial Mehr publicaba caricaturas ridiculizando al Presidente Obama por su "fracaso".

\section{El enfrentamiento .Jatamí - Ahmadinevad}

La elección del $9^{\circ}$ Maylis despertó interés fuera de Irán, pero no por la importancia del país ni la del propio Parlamento. Irán es, en estos momentos, un Estado aislado en el concierto internacional y con grandes problemas económicos debidos a las sanciones internacionales. El Maylis, a pesar de que constitucionalmente parece ser una Cámara con grandes poderes, en realidad carece de ellos; todas sus decisiones tienen que ser aprobadas por el Consejo de Guardianes, una especie de Tribunal Constitucional cuyos miembros son nombrados por el Guía Supremo, la mitad directamente, la mitad de forma indirecta a través del Jefe del Poder Judicial. El interés por la elección derivaba pues por el enfrentamiento desde el mes de abril entre el Presidente y el Guía Supremo. Algunos medios dijeron que la elección dejaría claro quién mandaba en Irán; otros hablaron de la lucha entre una teocracia dirigida por clérigos y una dictadura militar ejercida por el Cuerpo de Guardias Revolucionarios, el Pasdarán.

La realidad era otra y se derivaba de la ambivalencia de la denominación oficial del país: República Islámica. En Irán existen unas instituciones "Republicanas"- dirigidas, más o menos, por el Presidente- y otras "Islámicas", encabezadas por el Guía. A las dos se añade un sistema informal dominado por las alianzas, en su mayoría, clericales. El Guía nombra al Consejo de Guardianes que, como hemos visto controla el Maylis y valida a los candidatos a las elecciones, a todos los miembros del Consejo de Discernimiento, órgano que se encarga de arbitrar las posibles discrepancias entre el Maylis y los Guardianes, al Consejo Supremo de Defensa Nacional, que no es constitucional pero legisla, al Jefe del Poder Legislativo, a todos los mandos militares importantes y controla los medios de difusión públicos. Además, en todas las instituciones de importancia- civiles, militares, judiciales, religiosas, económicas- el Guía tiene un representante personal, que es sus ojos, oídos y voz, y cuenta con la mayoría del clero.

\section{La segunda vuelta de las elecciones legislativas iraníes}

La segunda vuelta para elegir el $9^{\circ}$ Maylis tuvo lugar el día 4 de mayo. La elección siguió las mismas pautas de todas las elecciones anteriores, y en particular, las de la primera vuelta del 2 de marzo. Idénticas llamadas a la participación popular, exaltación del nacionalismo iraní, apelación al deber religioso del voto y ataques al adversario político. Este adversario, como en marzo, ya no era el "reformismo" de la revolución verde de Musavi y Karrubi sino los "desviacionistas" partidarios del Presidente Ahmadineyad. Pero todo ello en un tono menor, 
como a escala reducida, en consonancia con el hecho de que en la primera vuelta se había peleado por 290 escaños y en la segunda sólo quedaban por cubrir 65 y también porque la composición del Maylis ya estaba prácticamente decidida.

La campaña electoral empezó el 26 de abril con 135 candidatos para los 65 escaños, en 33 circunscripciones de 19 provincias. El distrito electoral de mayor importancia era el de Teherán en la que quedaron sin cubrir 25 de las 30 vacantes.

En el campo de las descalificaciones y ataques al adversario cabe destacar que el ayatolá Mesbah Yazdi, el "marya" o guía espiritual de Ahmadineyad, el día 29 afirmó que, para el régimen islámico, son más peligrosos los "desviacionistas" seguidores del Presidente que los "reformistas" de Musavi y Karrubi. En el de las llamadas a la participación masiva, el discurso del 2 de mayo del Guía de Revolución, ayatolá Jamenei, en el que agradeció a la nación iraní su constante vigilancia para hacer fracasar los ataques del enemigo y, en consecuencia, le pidió una gran participación en los comicios.

El día 4, casi todos los políticos y clérigos importantes, incluidos los "reformistas", fueron a votar. Entre ellos Rafanyani, el adversario de Ahmadineyad, el nieto de Jomeini Hossein, que en otras ocasiones había criticado políticas del régimen, Musavi Koeiniha, el Secretario General de la Asociación de Clérigos Combatientes, asociación que siempre había estado aliada con los reformistas, y el Vicepresidente del Partido de la Confianza Nacional, el partido cuyo Jefe, Karrubi, seguía en arresto domiciliario. Como curiosidad se puede señalar que Rafsanyani, al depositar su voto, aprovechó para pedir a los iraníes expatriados que enviasen su dinero a Irán, para ayudar a resolver los problemas económicos, lo que da idea de la situación real de la República Islámica, a pesar de las tesis oficiales sobre la "ineficacia" de las sanciones internacionales.

Las facciones conservadoras encabezadas por el Frente Principalista obtuvieron un triunfo rotundo: el Frente obtuvo 41 escaños, mientras que el Frente de Resistencia Islámica de los partidarios del Presidente lograron 13 y 11 fueron para los independientes. En Teherán, los seguidores de Ahmadineyad consiguieron solamente 9 escaños de los 25 en juego. Sin embargo, es difícil asegurar la adscripción de los nuevos diputados a un grupo o a otro. En principio, las diferencias ideológicas entre los nuevos diputados son mínimas, sólo de matiz, ya que todos han pasado por la criba previa del Consejo de Guardianes; lo que cuenta son los intereses individuales o de grupo. Es interesante hacer notar que el dirigente de la alianza electoral "La Voz de la Nación" había declarado, ya antes de la primera vuelta, que no había diferencias entre "principalistas moderados" y "reformistas moderados".

En segundo lugar, la normativa iraní admite que un único candidato figure en las listas electoras de varios grupos; en el caso de Teherán, entre los cinco elegidos en la primera vuelta dos de ellos iban en las listas de los dos Frentes adversarios, el Principalista y el de Resistencia, y tres entre los de la segunda. En cuanto a los independientes, los nuevos miembros del Maylis eran personalidades de relieve local o provincial sin ideología política definida que votarían en la Asamblea en función de sus intereses inmediatos.

Según el Ministerio del Interior la participación fue muy alta, del orden de la de la primera vuelta (64\%), superando en un $10 \%$ la tasa de la segunda vuelta en las anteriores elecciones para el $8^{\circ}$ Maylis, en 2008. La verificación de los datos es imposible pues la República Islámica no permite la actuación de observadores extranjeros ni de organizaciones sociales. En esta elección, las autoridades emplearon, por primera vez y solamente en algunas provincias, un sistema informático de recuento de votos y envío de datos sin utilización de 
personal. En principio el sistema parece garantizar una mayor transparencia y la imposibilidad de manipulación; en realidad deja las manos libres al Ministerio de Interior. Lo más probable es que la participación rondase el $30 \%$.

El Ministro de Interior, ante las colas de votantes, prolongó dos veces el horario de las votaciones para permitir a la población el ejercicio del sufragio; los medios de comunicación dijeron que esas colas eran muy grandes y que los periodistas extranjeros estaban admirados y sorprendidos ente el entusiasmo de los iraníes; el Jefe del Estado Mayor, general Firuzabadi, fue el encargado de anunciar la gran afluencia de votantes y de agradecer la participación popular. Sin embargo, los periodistas relataron que los colegios electorales estaban casi desiertos.

Las cifras oficiales de las dos fases de la elección daban a las facciones conservadoras un total de 182 escaños, de ellos 98 al Frente Principalista y solamente 43 a los seguidores de Ahmadineyad. La victoria del Guía Supremo era clara y al Presidente le esperaba una etapa muy dura. El vicepresidente del Maylis y miembro del Frente Principalista, Mohamed Reza Bahonar, declaró, el 5 de mayo, que la nueva Asamblea "no sería obediente" al Gobierno ya que los diputados que sólo tienen en cuenta la posición de éste y le obedecen son, como mucho, "como los dedos de una mano", que el Frente de Resistencia carece de capacidad para controlar al Maylis y que, en realidad, no es un grupo de apoyo al Gobierno sino de "comportamientos radicales"

Ya el 14 de marzo, por primera vez en la historia del régimen islámico, el Maylis hizo comparecer al Presidente para preguntarle por ocho diferentes cuestiones presupuestarias y de política interior. Los diputados no quedaron satisfechos y calificaron la actitud del Presidente de "insultante". El 8 de abril una comisión del Parlamento rechazó las líneas generales del Presupuesto presentado por el Gobierno ${ }^{4}$ y el 17 la TV canceló la retrasmisión de un discurso presidencial. El Parlamento estudia, en la actualidad, la reprobación de tres ministros, entre ellos el de Trabajo, y ha iniciado una discusión sobre el procedimiento para reprobar al Presidente. Como una ley aprobada recientemente por el Maylis autoriza a éste a inspeccionar a los diputados, Ahmadineyad dirigió un escrito al jefe del Consejo de Guardianes, el ayatolá Shahroudi, calificando la ley de "discriminatoria" y "anticonstitucional". Shahroudi le contestó diciendo que es el Presidente quien tiene un comportamiento anticonstitucional pues al dirigirse directamente al Consejo, que no depende de él, invade competencias del Guía Supremo En estos momentos se debaten en Irán dos cuestiones políticas importantes: la primera es si la figura del presidente es necesaria y no sería mejor que la segunda autoridad de la república fuese un simple Primer Ministro dependiente directamente del Guía; la segunda, si el Maylis debería reprobar a Ahmadineyad forzando así su cese-Con respecto a la primera, el cambio sería muy complicado ya que obligaría a cambiar la Constitución, que es un proceso largo y difícil que acaba con un referéndum. Además, implicaría al Guía Supremo en los asuntos del día a día, perdiendo así su aureola de figura casi sagrada. Sobre la segunda, hay que decir que a Ahmadineyad le quedan sólo 10 meses de presidencia; no parece lógico que sea despedido y se tenga que organizar una nueva elección presidencial.

\footnotetext{
${ }^{4}$ Finalmente el presupuesto fue aprobado el 9 de mayo por un monto de 416.000 millones de dólares, con 128 votos a favor, 40 en contra y 27 abstenciones.
} 